\title{
Injuries to dancers: prevalence, treatment, and perceptions of causes
}

\author{
Ann Bowling
}

\begin{abstract}
A survey of injuries to dancers was commissioned by the National Organisation of Dance and Mime. Questionnaires asking about chronic and recent injuries were sent to 188 dancers and completed by 141 dancers from seven professional ballet and modern dance companies in the United Kingdom ( $75 \%$ response rate). It was found that of the 141 dancers, $67(47 \%)$ had experienced a chronic injury and $59(42 \%)$ an injury in the previous six months that had affected their dancing. A high proportion of injuries to the soft tissues had not responded to treatment. With correct treatment such injuries should usually heal completely.
\end{abstract}

Dancers are aware of the high rate of injuries and also of procedures that might help to prevent injury - for example, dancing on floors that are sprung and in warmer studios; teachers' and choreographers' awareness of a dancer's limitations and the need for rest and adequate treatment when an injury occurs.

\section{Introduction}

Injury is the most frequent medical problem among dancers of classical ballet and modern dance. ${ }^{1}$ There is widespread discussion and concern within both the casts and the managements of ballet and dance companies about the incidence of injuries and their impact on a dancer's career and on the ability of companies to perform their repertoire as scheduled.

In the United States several surveys of the incidence and nature of the injuries sustained by ballet dancers have been carried out, but no study has been conducted of the incidence of injury among dancers in the major professional companies in the United Kingdom.

Research in the United States suggests that pain in the lower leg is the most common problem among ballet dancers followed by problems associated with the knee, ankle, foot, and lower spine. ${ }^{2}$ Various factors have been claimed to predispose dancers to lower leg injuries, such as performing on hard unsprung floor surfaces, the demand for an exaggerated turn out from the hips, and the use of thin soled shoes or bare feet. ${ }^{2-4}$ Beyond this there has been little objective research of the predisposing cause of dance injuries.

The National Organisation for Dance and Mime was established in 1982 to represent dancers and similar performers. In 1986 it established a medical advisory panel, consisting of medical practitioners and related professionals and representatives of British ballet and dance companies. The panel is concerned with the medical needs and health care of all professional dancers.

Health Services Research

Unit,

Department of Public

Health and Policy,

London School of Hygiene and Tropical Medicine,

London WC1E 7HT

Ann Bowling, PHD, senior lecturer

BrMed f 1989;298:731-4

\section{Method}

A retrospective questionnaire survey that was designed by members of the medical advisory panel was aimed at determining the incidence of dance related injuries and establishing the dancers' perceptions of their causes, the potential for preventing them, and the availability and take up of treatment from professional therapists and others. A pilot study of the question- naire was carried out on dancers from a small company, which was then excluded from the main study.

The information collected was based on the dancers' self reports of injury and diagnosis. These were not validated by checking reports with medical records and therapists' records owing to the sensitive nature of the survey among dancers, who were assured of complete confidentiality. Although inevitably there are problems with recall when respondents are asked to document events that took place some time ago, ${ }^{56}$ good agreement is usually obtained between self reports and medical notes when questions are limited to recent time periods and to topics that pertain to respondents. ${ }^{7.10}$ To minimise bias owing to problems with recall the main part of the questionnaire asked only for further details about the injuries experienced over the previous six months.

\section{SAMPLE AND RESPONSE RATE}

In the United Kingdom there are three large classical ballet companies, two large modern dance companies, and many smaller, mainly modern, dance companies. Sampling dancers is not easy because they spend extensive periods of time on tour. It was decided to concentrate on all dancers from companies that were unlikely to be on tour at the time of the study. One large ballet company was also excluded from the study as it was undergoing administrative changes at the time. Two of the three large classical ballet companies, the two leading modern dance companies, and three of the eight minor professional dance companies known to the Arts Council or to the National Organisation for Dance and Mime were included in the study.

Questionnaires were sent to 188 dancers: the 139 classical dancers and the 49 modern dancers employed by these companies in spring 1987. According to figures from the Arts Council, there were 310 classical ballet dancers and 95 modern technique dancers employed in Britain. Thus the sample of dancers represented $46 \%$ of all dancers in employment in Britain at that time.

Of the 188 dancers, $83(44 \%)$ were men and 105 (56\%) were women. Responses were received from 141 dancers $(75 \%)$. For well designed questionnaire surveys a response rate of $75 \%$ or higher can be expected. ${ }^{11}$ The rate of $75 \%$ may be regarded as good for a survey of respondents who are often away on tour.

The sex distribution of the sample of dancers who responded was representative of that of the total sample. There were no statistically significant differences between non-responders and responders in relation to their style of dance - that is, classical or modern. It is not known whether they differed in their rates of injury.

\section{Results}

AGE, SEX, AND BODY MASS INDEX

Eighty (57\%) respondents were women and 61 (43\%) were men. Seventy five $(53 \%)$ respondents were born between 1961 and 1969 (aged 18-26 at the time of the survey), 46 (33\%) between 1951 and 1960 (aged 


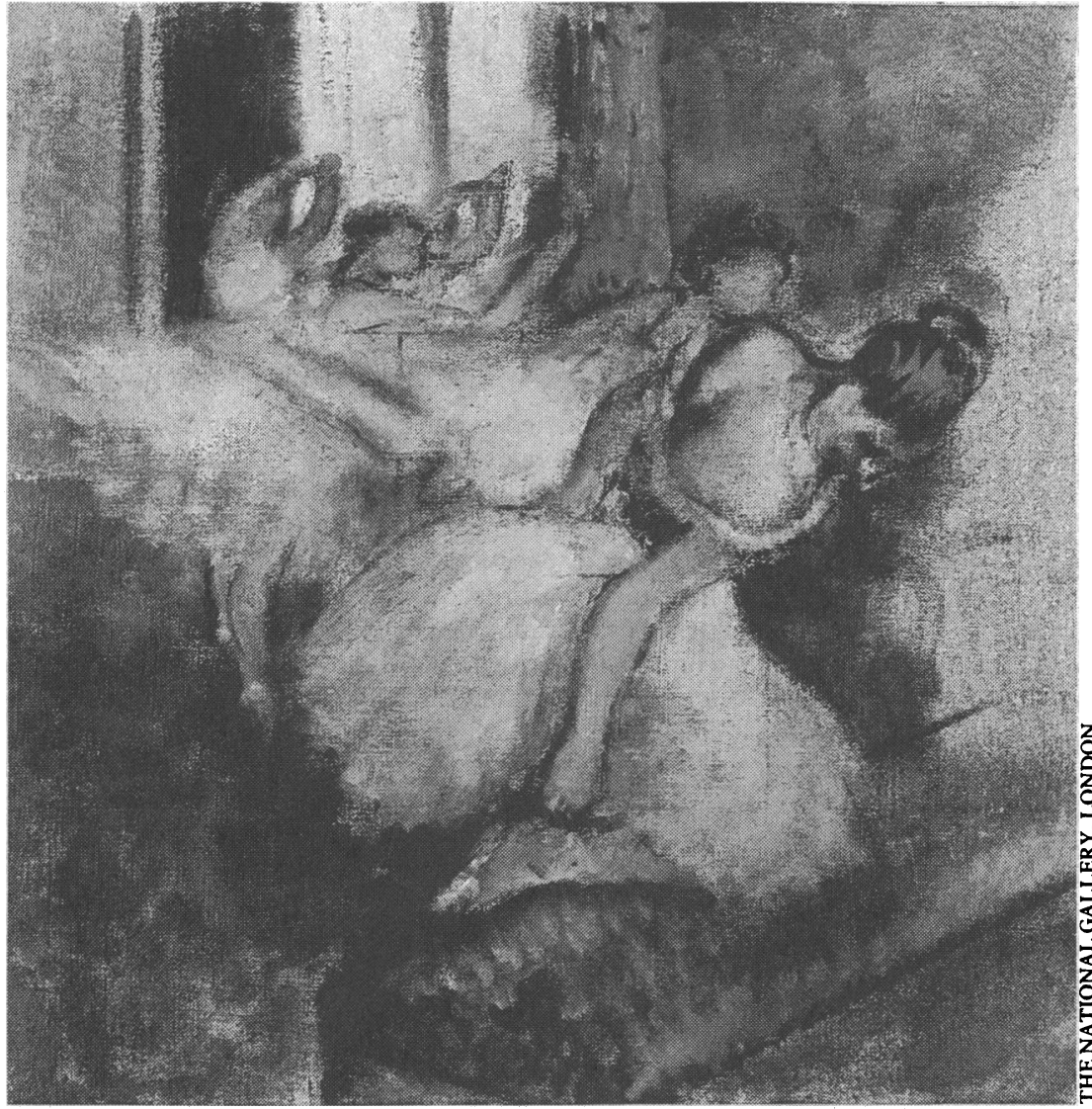

$27-36)$, and $20(14 \%)$ in or before 1950 (aged 37 or over).

Dancers were asked for details of their height and weight. The Quetelet index was calculated to estimate the body mass index (weight $(\mathrm{kg})$ divided by height (metres) squared). This is the most commonly used measure of adiposity.

As expected the mean values for body mass index for the dancers in the sample were lower than those for the general population in the same age groups (table I). Most of the women dancers had a body mass index below 19.00 (mean 18.52). This is below the normal ranges for women of similar ages in the general population: the means for national samples of women aged between 20 and 40 are between $22 \cdot 7$ and 23.9..$^{12-14}$

For most of the men dancers the body mass index was 21 or over (mean 20.97). This also is below the normal ranges for men of similar ages: the means for national samples of men aged between 20 and 40 are between 23 and $24 \cdot 8 . .^{12-14}$

There were no significant differences between body mass index and age in either men or women.

\section{EXPERIENCE OF INJURY}

Respondents were asked about the total number and sites of injuries that they had ever sustained that had affected their dancing in any way, chronic injuries that gave them continuing problems, and injuries sustained that had affected their dancing in the previous six months. Information was not collected about minor injuries.

Table II shows that about four fifths (118) of the dancers reported having had at least one injury at some time that had affected their dancing, and almost half (67) reported that they were currently suffering from at least one chronic injury that gave them continuing problems. Of the last group, 23 dancers reported having had two or three chronic injuries. Fifty nine $(42 \%)$ had sustained at least one injury in the previous six months which had affected their dancing, and four of these dancers had experienced two or three injuries.
TABLE II-Proportion of dancers who had sustained injuries at some time or had chronic injuries

\begin{tabular}{lcc}
\hline & \multicolumn{2}{c}{ No (\%) of dancers who: } \\
\cline { 2 - 3 } No of injuries & $\begin{array}{c}\text { Had ever had injury } \\
\text { that affected dancing }\end{array}$ & $\begin{array}{c}\text { Had chronic injury } \\
\text { causing continuing } \\
\text { problems }\end{array}$ \\
\hline None & $22(16)$ & $74(53)$ \\
1 & $42(30)$ & $39(28)$ \\
2 & $34(24)$ & $26(18)$ \\
3 & $14(10)$ & $2(1)$ \\
4 & $10(7)$ & \\
$5-12$ & $17(12)$ & 141 \\
$\geqslant 13$ & $1(1)$ & \\
\hline No of respondents & 140 & \\
\hline
\end{tabular}

TABLE III - Site of chronic injuries that gave continuing problems and of injuries sustained in previous six months sufficient to affect dancing

\begin{tabular}{|c|c|c|}
\hline \multirow[b]{2}{*}{ Site } & \multicolumn{2}{|c|}{ No (\%) of dancers with: } \\
\hline & Chronic injuries & $\begin{array}{l}\text { Injuries in previous } \\
\text { six months }\end{array}$ \\
\hline Back/neck (including vertebrae) & $19(29)$ & $15(26)$ \\
\hline Ankle & $13(20)$ & $11(19)$ \\
\hline Knee & $11(17)$ & $7(12)$ \\
\hline Thigh/leg & $10(16)$ & $6(10)$ \\
\hline Other body: (hip/groin/ribs) & $4(6)$ & $7(12)$ \\
\hline Foot/toes & $4(6)$ & $9(16)$ \\
\hline Upper limb (shoulder/wrist/hand) & $4(6)$ & $3(5)$ \\
\hline No of respondents & $65^{\star}$ & $58+$ \\
\hline $\begin{array}{l}{ }^{\star} \text { Total of } 65 \text { dancers as two did not } \\
\text { †Total of } 58 \text { dancers as one did not }\end{array}$ & $\begin{array}{l}\text { give details of site. } \\
\text { ive details of site. }\end{array}$ & \\
\hline
\end{tabular}

Table III gives the sites of chronic injuries that gave continuing problems and of the injuries experienced over the previous six months. The back or neck, or both, and ankle were the most common sites of injury. For the dancers with chronic injuries muscular injuries were most common $(31 ; 48 \%)$ followed by fractures and dislocations $(14 ; 22 \%)$.

The back or neck, or both, and ankle were also the most frequently reported sites of injury over the previous six months. In addition, injuries to the foot and toes were reported by an appreciable minority of dancers. The most common type of recent injury was again soft tissue injury: $35(60 \%)$ of 58 dancers responding with an injury over the previous six months reported sprains, strains, tears, or pulls of muscles or ligaments; a further seven (12\%) reported bad bruising, swelling, or inflammation of muscles or tissues. Seven (12\%) reported fractures (ankle one; vertebrae one; "shin splint" one; foot or toes, or both, four) and nine (16\%) reported dislocated joints, problems with the back (including vertebrae), and injuries to cartilage.

There were no differences by age, sex, body mass index, and type of dancer (classical or modern) with experience of injury.

\section{PLACE RECENT INJURY OCCURRED AND CAUSE}

Of the injuries that had occurred in the previous six months, 19 (32\%) happened during a performance, $16(28 \%)$ during rehearsals, and nine $(16 \%)$ during classes. A further four (7\%) dancers said that they had a slow onset injury and did not know where it had occurred, and $10(17 \%)$ mentioned various situations.

Most dancers thought that their injuries were due to feeling overtired, run down, overworked, and under strain and pressure (reported by $21(38 \%)$ ). Other perceived causes were dancing on unsuitable stages and flooring (such as hard, unsprung floors) 14 (25\%); dancing in cold, draughty environments and being insufficiently warmed up (eight (14\%)); the demands of difficult choreography (seven, $12 \%$ ); and the continual repetition of difficult movements during rehearsals 
(four, 7\%). A further $22(39 \%)$ mentioned a variety of reasons including inadequate diets, falls due to partnering difficulties, and forced turn out from the hips (percentages total more than $100 \%$ as some dancers gave more than one reason).

\section{TREATMENT RECEIVED}

Thirty one (54\%) dancers said that immediately they were injured they carried on as best as they could and did not rest at all, six (10\%) carried on for a few davs (until the next rehearsal or performance) and then stopped and rested, and one dancer had carried on for three to five months until she stopped and rested. Just $19(32 \%)$ stopped dancing and rested immediately an injury occurred. Of the 26 dancers who stopped and rested immediately or later on, nine $(35 \%)$ rested for a week or less, nine $(35 \%)$ for between one and four weeks, five $(20 \%)$ for two months, and three $(10 \%)$ for three months or more.

All 59 dancers who had been injured in the previous six months in a way that affected their dancing consulted a health professional; $37(63 \%)$ consulted more than one professional. Table IV shows that a physiotherapist was the professional consulted by most dancers. Medically qualified practitioners were consulted by less than half of all dancers.

TABLE IV-Type of professional consulted for injuries occurring in previous six months by type of dance company

\begin{tabular}{lccc}
\hline & \multicolumn{2}{c}{$\begin{array}{c}\text { No }(\%) \text { of consultations } \\
\text { for dancers in: }\end{array}$} \\
\cline { 2 - 3 } & $\begin{array}{l}\text { Classical } \\
\text { company }\end{array}$ & $\begin{array}{c}\text { Modern } \\
\text { company }\end{array}$ & Total ${ }^{\star} \dagger$ \\
\hline Professional & $37(86)$ & $8(50)$ & $45(76)$ \\
\hline Physiotherapist & $25(58)$ & $3(19)$ & $28(47)$ \\
Medically qualified practitioner & $11(26)$ & $6(38)$ & $17(29)$ \\
$\quad$ (general practitioner or specialist) & $7(16)$ & $5(31)$ & $12(20)$ \\
Masseur & $4(9)$ & $9(56)$ & $13(22)$ \\
Acupuncturist & $1(2)$ & $4(25)$ & $5(8)$ \\
Osteopath & 43 & 16 & 59 \\
Other & & &
\end{tabular}

*Percentages total more than $100 \%$ as some dancers saw more than one type of professional.

tDifferences between groups in relation to individual type of practitioner consulted were not statistically significant, possibly owing to small base numbers.

Just over three quarters (22) of the dancers who consulted a medical doctor did so privately, and most (19) of these were covered by a medical insurance scheme for the costs. The remainder said that they were covered by an insurance scheme for consultations and treatment with a complementary medical practitioner or physiotherapist but not a medical doctor.

Ten (18\%) of the 57 injured dancers who responded to this question saw a professional for treatment or advice on the day of the injury, and $18(32 \%)$ saw someone the day after the injury. Twelve $(21 \%)$ delayed two to four days before seeking help, $14(24 \%)$ delayed five to 14 days, and three $(6 \%)$ delayed longer. The reasons for the delay varied but the one given most frequently (by $10(21 \%)$ ) was that professional help was not available when the injury occurred on tour, and for a further $10(21 \%)$ there were delays in obtaining appointments with medical specialists.

All but two of the dancers said that they were offered treatment by the professional they consulted, and all but two of these took up the treatment. Forty three $(83 \%)$ found the treatment helpful, six $(11 \%)$ said that it was still too early to assess, and three $(6 \%)$ found the treatment unhelpful.

Of the 59 dancers who had sustained an injury in the previous six months, $26(44 \%)$ said it had healed by the time of the survey, $32(54 \%)$ said it had not healed, and for one dancer treatment was continuing. Those whose injury had not healed were asked if they expected complete recovery: $17(52 \%)$ said yes, three $(10 \%)$ said no, and $13(38 \%)$ were uncertain.

\section{PREVENTION}

The main suggestions for preventing injury made by the 114 dancers who responded were good technique classes taken by teachers who were aware of anatomy and the body's limitations (mentioned by $57(50 \%)$ ); careful warming up exercises before vigorous movements $(41 ; 36 \%)$; warmer studios, theatres, and rehearsal rooms $(36 ; 32 \%)$; less pressure and overwork $(33 ; 29 \%)$; better flooring in theatres and studio (sprung, even, non-raked, non-slip) (22;19\%) resident physiotherapists or masseurs for injury prevention treatment $(22 ; 19 \%)$; and adequate diets $(20 ; 18 \%)$. A further $10(9 \%)$ made other suggestions Most respondents made more than one suggestion.

\section{Discussion}

The results of this survey show an extensive level of injuries among both classical ballet and modern technique professional dancers. Most (84\%) had experienced an injury sufficient to affect their dancing at some time, about half had a chronic injury that gave them continuing problems, and just over two fifths had sustained at least one injury in the previous six months that had affected their dancing.

Although the figure relating to injuries eve experienced is likely to be an underestimate owing to poor recall, the figures relating to current chronic injuries and injuries experienced over the previous six months seem to be valid indicators of prevalence. There is, however, no information about the prevalence of injury among the $47(25 \%)$ non-responders. Therefore it is not known whether they provide a source of bias. In addition, the cross sectional survey design might be a further source of bias, leading to an underestimate of injury by excluding dancers who may have been forced to retire prematurely owing to injury. Only a longitudinal survey could overcome the latter problem. The results of this study are nevertheless valuable as there is no other information about the prevalence or type of injuries to dancers in the United Kingdom.

Consistent with research findings in the United States, the back and lower limb were shown to be particularly vulnerable to injury. ${ }^{2}$ The most common types of injury were sprained, strained, pulled, or torn muscles and ligaments, although there were also several cases of fractures. Unlike in the survey carried out in the United States there were relatively few cases of shin splints (pain in lower leg), ${ }^{2}$ although injuries to the lower limb were common. The difference may be due to confusion over terminology in the case of shin splints.

Injuries to the soft tissues comprised almost two thirds of injuries occurring in the previous six months; they also accounted for nearly half of chronic injuries. It is disturbing that this was the largest group of injuries that had not resolved. Doctors believe that with correct treatment the recovery rate for injuries to soft tissues is nearly $100 \% .^{15}$ Perhaps injuries to soft tissues are not taken seriously enough by dancers and companies: just a third of dancers stopped dancing and rested immediately on being injured. In addition, less than half had consulted a medically qualified practitioner. Medical practitioners who specialise in dance medicine believe that the consequences of ignoring an injury when it occurs can have serious effects on a dancer's career. ${ }^{15}$

The dancers were aware of preventive procedures, and it seems that practical remedies could be undertaken: sprung and even floors and warmer studios should be provided; teachers and choreographers 
should be more aware of a dancer's limitations and of dancers' needs to rest as soon as injuries occur; and dancers need immediate access to adequate treatment.

The profession of dance is believed to be fairly conservative in responding to recommended changes. The current climate within the profession, however, is ripe for initiating discussions about preventing injuries to dancers, given the awareness of dancers of the high rates of injury and the increasing interest in the potential of sports and dance medicine.

I thank Dr Richard Pearson for his contribution and advice; $\mathrm{Mr}$ Justin Howse and the National Organisation for Dance and Mime Medical Advisory Panel for their help; the following companies and their administrators who made the survey a reality: the Royal Ballet, London Contemporary Dance Theatre, Sadler's Wells Royal Ballet, Diversions Dance Company, Rambert Dance Company, Dundee Repertory Dance Company, English Dance Theatre; the Calouste Gulbenkian Foundation and British Actors Equity Association for their generous sponsorship; the Arts Council of Great Britain for information; and the National Organisation for Dance and Mime executive for their help and support.
1 Anonymous. Bionic ballerinas [Editorial]. Lancet 1985;ii:481-2. 2 Washington EL, Musculoskeletal injuries in theatrical dancers: site, frequency, and severity. Am F Sports Med 1978;6:75-97.

quency, and severity. Am 7 Sports Med 1978,6:75-97.

4 O'Donoghue DH. Treatment of injuries to athletes. Philadelphia: Saunders, 1962.

5 Carlsson GS. Validity of injury data collected by interview: a study of men born in 1913 and 1923. F Neurol Neurosurg Psychiatry 1983;46:818-23.

6 Langley JD, Silva PA, Williams SM. Absence of psychosocial bias in the under-reporting of unintentional childhood injuries. $\mathcal{F}$ Epidemiol Community Health 1988;42:76-82.

7 United States Department of Health, Education and Welfare. Experiments in interviewing techniques: field experiments in health reporting, 1971-1977. Ann Arbor: National Center for Health Services Research, University of Michigan, 1977.

8 Martin C. Monitoring maternity services by postal questionnaire: congruity between mothers' reports and their obstetric records. Stat Med 1987;6: 613-27.

9 Draper J, Field S, Thomas H. The early parenthood project: an evaluation of a community ante-natal clinic. Cambridge: Hughes Hall, 1984.

10 Cartwright A Smith C. Some comparisons of data from medical records and from interviews with women who had recently had a live birth or stillbirth J Biosoc Sci 1979;11:49-64.

11 Cartwright A. Health surveys. London: King's Fund, 1983.

12 Department of Health and Social Security and Medical Research Council. In James WPT, comp. Report on research on obesity. London: HMSO, 1976. 13 Royal College of Physicians. Obesity. London: RCP, 1983.

14 Cox BD, Blaxter M, Buckle AJL, et al. The health and lifestyle survey. London Health Promotion Research Trust, 1987.

15 Howse J, Hancock S, eds. Dance techniques and injury prevention. London: Black, 1988

(Accepted 16 December 1988)

\section{For Debate}

\section{AIDS on the death certificate: the final stigma}

\author{
Michael B King
}

Births, deaths, and marriages have been recorded for centuries in England and Wales. The first attempt to keep a record for the whole nation dates from the time of Henry VIII, and even in the Tudor era efforts were made to start a central registry.' The main impetus arose from a desire for marriage to be accredited a proper degree of publicity and regularisation by a civil authority as well as for a source of documentary proof of age, legitimacy, and ancestry. Reformers in the early nineteenth century such as Edwin Chadwick were the first to realise the advantage of a central registry for monitoring social conditions and health. Chadwick pressed the government for a cause of death to be included in the death register, partly out of interest in infant mortality, which was known to be a sensitive indicator of social conditions.

\section{Accuracy of certification}

Registration thus became constitutional law in 1836 , and physicians have been entreated ever since to accurately record the cause of death. Although the system has proved worth while in a legal and medical sense, ${ }^{2}$ the accuracy of death certification has been vigorously debated, particularly in this century in medical journals in Europe and the United States. Scrutiny of records has revealed incorrect clinical diagnosis, clerical errors, ${ }^{3.5}$ and confusion of "mode" of death with "cause" of death, resulting in imprecision and delay for relatives. ${ }^{56}$ Cynics have even depicted the statistical data from death certification as "rubbish in-rubbish out." Although findings at necropsy increase the accuracy of medical information, ${ }^{8}$ morbid anatomical and histopathological findings may have no direct connection with the fatal outcome. ${ }^{3}$ Indeed, death certificates issued by coroners who are not usually medically trained which contain a summary of morbid anatomical findings may conceal the greatest number of errors in relation to the actual cause of death. ${ }^{9}$

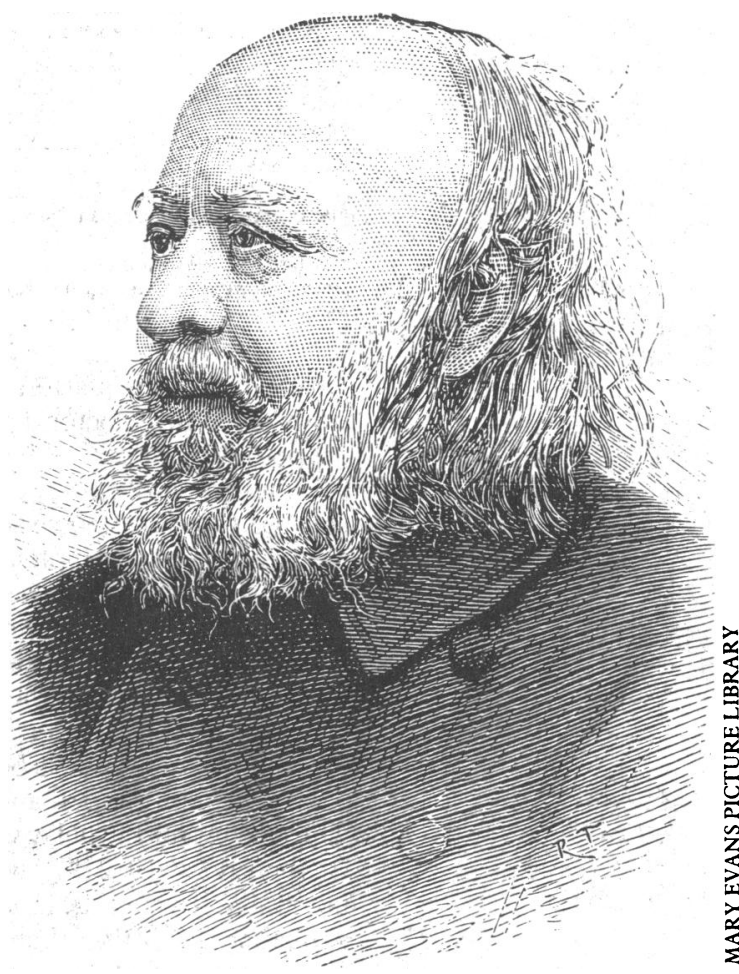

Sir Edwin Chadwick, public health reformer of the early nineteenth century, who realised the importance of notifying the cause of death

\section{Stigma of cause of death}

Until the advent of AIDS more liberal attitudes in society had lessened the stigma of most causes of death as an obstacle to their accurate certification. ${ }^{810}$ Before a change in the law in England and Wales in 1984 chronic alcoholism was considered to be within the broad remit of unnatural deaths due to poisoning and was therefore subject to a public inquest. To avoid
Michael B King, MRCPSYCH, senior lecturer 